\title{
Physiological constraints on the global distribution of Trichodesmium - effect of temperature on diazotrophy
}

\author{
E. Breitbarth ${ }^{1, * * *}$, A. Oschlies ${ }^{2, * * *}$, and J. LaRoche ${ }^{1}$ \\ ${ }^{1}$ Leibniz-Institute of Marine Sciences, IFM-GEOMAR, Düsternbrooker Weg 20, 24105 Kiel, Germany \\ ${ }^{2}$ National Oceanography Centre, Southampton, European Way, Southampton, SO14 3ZH, UK \\ "now at: Department of Chemistry, Analytical and Marine Chemistry, Göteborg University, Kemivägen 10, 41296 Göteborg, \\ Sweden \\ ** now at: Division of Applied Geology, Department of Applied Chemistry and Geosciences, Luleå University of Technology, \\ 97187 Luleå, Sweden \\ *** now at: Leibniz-Institute of Marine Sciences, IFM-GEOMAR, Düsternbrooker Weg 20, 24105 Kiel, Germany
}

Received: 7 April 2006 - Published in Biogeosciences Discuss.: 26 June 2006

Revised: 6 November 2006 - Accepted: 5 December 2006 - Published: 15 January 2007

\begin{abstract}
The cyanobacterium Trichodesmium is an important link in the global nitrogen cycle due to its significant input of atmospheric nitrogen to the ocean. Attempts to incorporate Trichodesmium in ocean biogeochemical circulation models have, so far, relied on the observed correlation between temperature and Trichodesmium abundance. This correlation may result in part from a direct effect of temperature on Trichodesmium growth rates through the control of cellular biochemical processes, or indirectly through temperature influence on mixed layer depth, light and nutrient regimes. Here we present results indicating that the observed correlation of Trichodesmium with temperature in the field reflects primarily the direct physiological effects of temperature on diazotrophic growth of Trichodesmium. Trichodesmium IMS-101 (an isolate of T. erythraeum) could acclimate and grow at temperatures ranging from 20 to $34^{\circ} \mathrm{C}$. Maximum growth rates $\left(\mu_{\max }=0.25 \mathrm{day}^{-1}\right)$ and maximum nitrogen fixation rates $\left(0.13 \mathrm{mmol} \mathrm{N}\right.$ mol $\left.\mathrm{POC}^{-1} \mathrm{~h}^{-1}\right)$ were measured within 24 to $30^{\circ} \mathrm{C}$. Combining this empirical relationship with global warming scenarios derived from stateof-the-art climate models sets a physiological constraint on the future distribution of Trichodesmium that could significantly affect the future nitrogen input into oligotrophic waters by this diazotroph.
\end{abstract}

\section{Introduction}

The diazotrophic filamentous cyanobacterium Trichodesmiumplays a key role in the nitrogen and carbon cycles of oligotrophic oceans, contributing up to $80 \mathrm{Tg}$ of

Correspondence to: E. Breitbarth

(eike@chem.gu.se) fixed nitrogen $\mathrm{yr}^{-1}$ (Capone et al., 1997). This represents a major fraction of the total marine pelagic nitrogen fixation, currently estimated at $110 \mathrm{Tg} \mathrm{yr}^{-1}$ (Gruber and Sarmiento, 1997). Furthermore, Trichodesmium can account for up to $47 \%$ of the primary production in the tropical North Atlantic Ocean (Carpenter et al., 2004) and contributes to export production via nitrogen fueling of the phytoplankton community (Letelier and Karl, 1996; Karl et al., 1997). Trichodesmium abundance is generally limited to oligotrophic waters and its observed temperature distribution range $\left(20^{\circ} \mathrm{C}-30^{\circ} \mathrm{C}\right)$ is also used to constrain $\mathrm{N}_{2}$-fixation in ocean biogeochemical circulation models (OBCMs) (Fennel et al., 2001; Hood et al., 2001, 2004). The upper temperature limit is set by the current sea surface temperature (SST) maximum and not by observed physiological constraints of high temperature on Trichodesmium distribution. Parametrizations are based solely on field correlations and cannot differentiate between direct physiological effects of temperature on an organism from indirect effects caused by changes in the physical environment (i.e. light and nutrients) induced by temperature, and thus are of limited predictive value.

Occurrence of Trichodesmium at higher latitudes with water temperatures below $20^{\circ} \mathrm{C}$ appears to be due to drift rather then local net growth. Nitrogen fixation by Trichodesmium was not observed in these waters (Carpenter, 1983; Lipschultz and Owens, 1996), although diazotrophic growth at temperatures close to freezing has been reported for other cyanobacteria, i.e. Oscillatoria sp. (Pandey et al., 2004) or Nostoc sp. (Zielke et al., 2002). An upper temperature limit cannot readily be derived from field observations because the present sea surface temperatures rarely reach the observed upper tolerance limit for Trichodesmium (Capone et al., 1997). A few exceptions are found where blooms of

Published by Copernicus GmbH on behalf of the European Geosciences Union. 
Trichodesmium have been reported at water temperatures as high as $35^{\circ} \mathrm{C}$. However, these high temperatures may have been due to intense surface heating by heat absorption of the dense Trichodesmium mat and probably resulted in rapid cell lysis and death (Capone et al., 1998).

While these empirical field correlations may be useful for parameterization of models, they provide no information on the direct physiological effect of temperature on the growth, nitrogen fixation, and C:N stoichiometry in Trichodesmium. A parameterization of models using a physiological basis for the apparent temperature control of Trichodesmium distribution would provide an additional predictive value.

Here we present effects of temperature on nitrogen fixation, POC:PON and Chl- $a$ :POC stoichiometry, and growth for Trichodesmium IMS-101. We discuss the possible physiological basis for these effects relative to other factors, such as light and nutrients, also affecting the distribution of Trichodesmium. Based on climate model predictions of the sea surface temperature increase within this century, we point out the importance of understanding the physiological temperature limits of Trichodesmium growth for predicting oceanic nitrogen input by this diazotroph with OBCMs in the future.

\section{Materials and methods}

\subsection{Growth of cultures}

An axenic culture of Trichodesmium IMS-101 was grown at temperatures ranging between 15 and $36^{\circ} \mathrm{C}$ for at least three transfers (minimum of 15 generations) at each temperature, under a light:dark cycle of 12:12 h and a light intensity of $100 \mu$ mol quanta $\mathrm{m}^{-2} \mathrm{~s}^{-1}$ using phosphorus and iron replete YBC II media without dissolved nitrogen added (Chen et al., 1996). In order to acclimate Trichodesmium the cultures were transferred from the respective higher or lower temperatures where growth was detected as well as from wellgrowing stock cultures incubated at $25^{\circ} \mathrm{C}$. Three independent attempts were made to acclimate Trichodesmium to grow at temperatures lower than $20^{\circ} \mathrm{C}$ and above $34^{\circ} \mathrm{C}$ without success.

\subsection{Nitrogen fixation measurements}

Nitrogen fixation rates were measured using the Acetylene Reduction Assay (ARA) (Capone, 1993), with calculations modified after Breitbarth et al. (2004) and a ratio of $\mathrm{C}_{2} \mathrm{H}_{2}$ reduced: $\mathrm{N}_{2}$ reduced of 4:1 (Montoya et al., 1996). Gas samples were analyzed on a Shimadzu GC-19B gas chromatograph equipped with a flame ionization detector and a $30 \mathrm{~m}$ long, wide bore $(0.53 \mathrm{~mm})$ capillary column (AluminaPlot ${ }^{\circledR}$, Resteck, USA). The oven temperature was set at $40^{\circ} \mathrm{C}$, injector and detector temperature at $200^{\circ} \mathrm{C}$, and the carrier gas flow $\left(\mathrm{N}_{2}\right)$ at $14.5 \mathrm{ml} \mathrm{min}^{-1}$, which yielded optimal peak separation and detection limits. The effect of temperature on nitrogen fixation was determined on batch cultures that were grown at $25^{\circ} \mathrm{C}$ and diluted daily with fresh media to maintain a constant biomass at the maximum growth rate in order to reduce the effect of growth phase on nitrogen fixation rates. For each temperature, three replicates were incubated simultaneously for $4 \mathrm{~h}(10: 00-14: 00 \mathrm{~h})$ during the middle of the light cycle in $20.2 \mathrm{ml}$ headspace vials containing $19 \mathrm{ml}$ culture and $1.2 \mathrm{ml}$ headspace with $0.4 \mathrm{ml}$ acetylene added. Additionally, the complete experiment was repeated three times. Nitrogen fixation rates were normalized to POC biomass.

\subsection{Biomass and elemental stoichiometry}

For biomass determinations, samples were filtered (GF/F, pre-combusted for elemental analysis) and stored at $-20^{\circ} \mathrm{C}$ until further analysis.

Particulate organic nitrogen (PON) and particulate organic carbon (POC) contents of the cultures were determined after Sharp (1975) and Ehrhard and Koeve (1999). Frozen filters were dried for $48 \mathrm{~h}$ at $45^{\circ} \mathrm{C}$ and thereafter subjected to analysis using an elemental analyzer (Euro-EA, Hekatech, Germany) equipped with a chromium oxide/cobalt oxide oxidation reactor, a copper reduction reactor, and a separation column maintained at an oven temperature of $45^{\circ} \mathrm{C}$. Carrier gas flow (He) was set at $96 \mathrm{ml} \mathrm{min}^{-1}$. The data were blank corrected using measurements of identically treated filters without culture material.

The chlorophyll- $a$ concentrations were determined fluorometrically based on Welschmeyer (1994) after bursting the cells in $90 \%$ Acetone by shaking and refreezing for $24 \mathrm{~h}$. Results obtained from this simple extraction method were comparable to those involving mechanical disruption of the cells (data not shown).

Maximum specific growth rates $(\mu)$ were determined by identifying the exponential growth phase in the batch cultures and applying a linear fit to the respective naturallogarithm-transformed POC, PON, and Chl- $a$ values. The slope of the regression represents the growth rate.

\subsection{Photosystem response measurements}

The photosynthetic quantum yield efficiency of the photosystem II was measured using a PhytoPAM equipped with Optical Unit ED-101US/MP (Walz, Germany) based on Kolbowski and Schreiber (1995). The ratios of variable to maximal fluorescence $\left(\mathrm{F}_{v} / \mathrm{F}_{m}\right)$ of Trichodesmium IMS-101 in response to different incubation temperatures were recorded over the complete growth period of the cultures at the respective temperatures. Further, $\mathrm{F}_{v} / \mathrm{F}_{m}$ was measured on cultures grown at $25^{\circ} \mathrm{C}$ after short-term exposure $(4 \mathrm{~h})$ to a temperature range of $14^{\circ} \mathrm{C}$ to $36^{\circ} \mathrm{C}$. These measurements were performed on the identical samples as used for the nitrogen fixation measurements described above. Samples were darkadapted for $10 \mathrm{~min}$ prior to the measurements. 

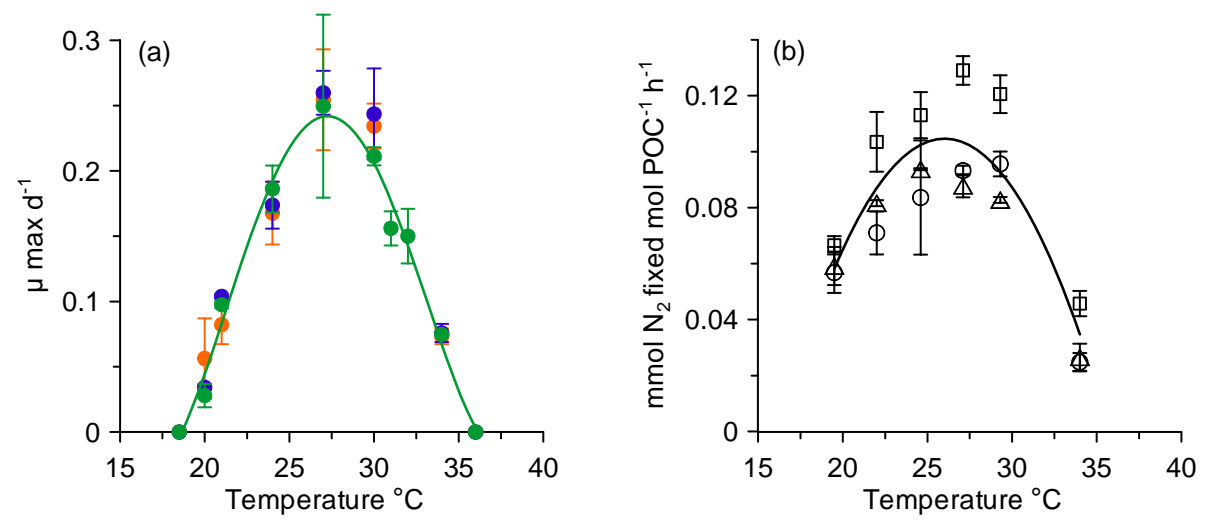

Fig. 1. (a) Maximum carbon (x, orange), nitrogen (x, blue) and chlorophyll-a (x, green) specific growth rates ( $\left.\mu_{\max }\right)$ as a function of temperature. The green curve gives the best fit to the chlorophyll- $a$ specific growth data using the polynomial function:

$\mu=2.29^{-5} x^{4}-2.50^{-3} x^{3}+9.71^{-2} x^{2}+1.58 x+9.15$

where $x$ is temperature in ${ }^{\circ} \mathrm{C}\left(\mathrm{R}^{2}=0.98\right)$. (b) Carbon specific nitrogen fixation rates as a function of temperature. Different symbols denote measurements from three independently performed identical experiments. Mean values of three replicates each are plotted with error bars showing standard deviations. The curve gives the best fit using the polynomial function:

$y=-0.001096 x^{2}+0.057 x-0.637$

where $x$ is the arithmetic mean of all measurements at the each temperature $\left(\mathrm{R}^{2}=0.97\right)$.

\subsection{Sea surface temperature increase predictions}

Predictions of the increase in sea surface temperature (SST) were based on two coupled atmosphere-ocean general circulation models (HadCM3 and GFDL R30). Both models predict a SST increase of up to $3^{\circ} \mathrm{C}$ by 2090 in our area of interest $\left(20-30^{\circ} \mathrm{C}\right.$ isotherms). The HadCM3 model run (Gordon et al., 2000) is based on the assumption that future emissions of greenhouse gases will follow the IS92a "business as usual" scenario with observed atmospheric $\mathrm{CO}_{2}$ concentrations until 1990 and a $1 \%$ annual increase thereafter (http://www.met-office.gov.uk/research/ hadleycentre/models/modeldata.html).

This prognosis is generally consistent with results from a similar experiment using the GFDL R30 climate model (Delworth et al., 2002) (http://www.gfdl.noaa.gov/ kd/ ClimateDynamics/NOMADS/index.html). The SST changes predicted by the climate models over the next century are then added to current annual mean SSTs (Levitus and Boyer, 1994) and the area of various physiologically relevant temperature ranges is computed.

\section{Results}

\subsection{Growth and nitrogen fixation}

Our results demonstrate that Trichodesmium IMS-101 grows and fixes nitrogen at temperatures between $20-34^{\circ} \mathrm{C}$ (Figs. 1a, b). The cultures did not grow below $20^{\circ} \mathrm{C}$ or above $34^{\circ} \mathrm{C}$. They could be maintained alive at $17^{\circ} \mathrm{C}$ for several weeks, but biomass progressively decreased. Incubations at water temperatures of $36^{\circ} \mathrm{C}$ resulted in cell death and lysis after two days (data not shown). Growth rates at each specific temperature did not differ significantly between chlorophyll-a, carbon or nitrogen specific growth, with the exception of carbon and nitrogen specific growth rates being higher than chlorophyll specific growth rates at $30^{\circ} \mathrm{C}$. No differences in growth rates were detected when cultures were transferred from similar or adjacent incubation temperatures or originated from $25^{\circ} \mathrm{C}$ incubations. Maximum specific growth rates $\left(\mu_{\max }\right)$ of the axenic Trichodesmium IMS101 strain were highest in the temperature range between 24$30^{\circ} \mathrm{C}$, with a peak at $27^{\circ} \mathrm{C}\left(\mu_{\max }\right.$ carbon specific $=0.25 \mathrm{day}^{-1}$, Fig. 1a). Growth rates were significantly reduced below and above this temperature range.

Nitrogen fixation rates were significantly affected by temperature and followed closely the relationship observed for growth rate with temperature, showing a temperature optimum between $24-30^{\circ} \mathrm{C}$ as well. The maximum nitrogen fixation rate of $0.13 \mathrm{mmol} \mathrm{N} \mathrm{mol} \mathrm{POC}^{-1} \mathrm{~h}^{-1}$ was measured at $27^{\circ} \mathrm{C}$. Three individual experiments with semi-continuously growing cultures yielded a similar temperature dependence (Fig. 1b).

\subsection{Elemental stoichiometry}

These observations were supported by measurements of elemental stoichiometry. The cellular carbon to nitrogen ratio increased from 5.4 (mol:mol) at $20^{\circ} \mathrm{C}$ to a maximum of 6.8 
$17^{\circ} \mathrm{C}$
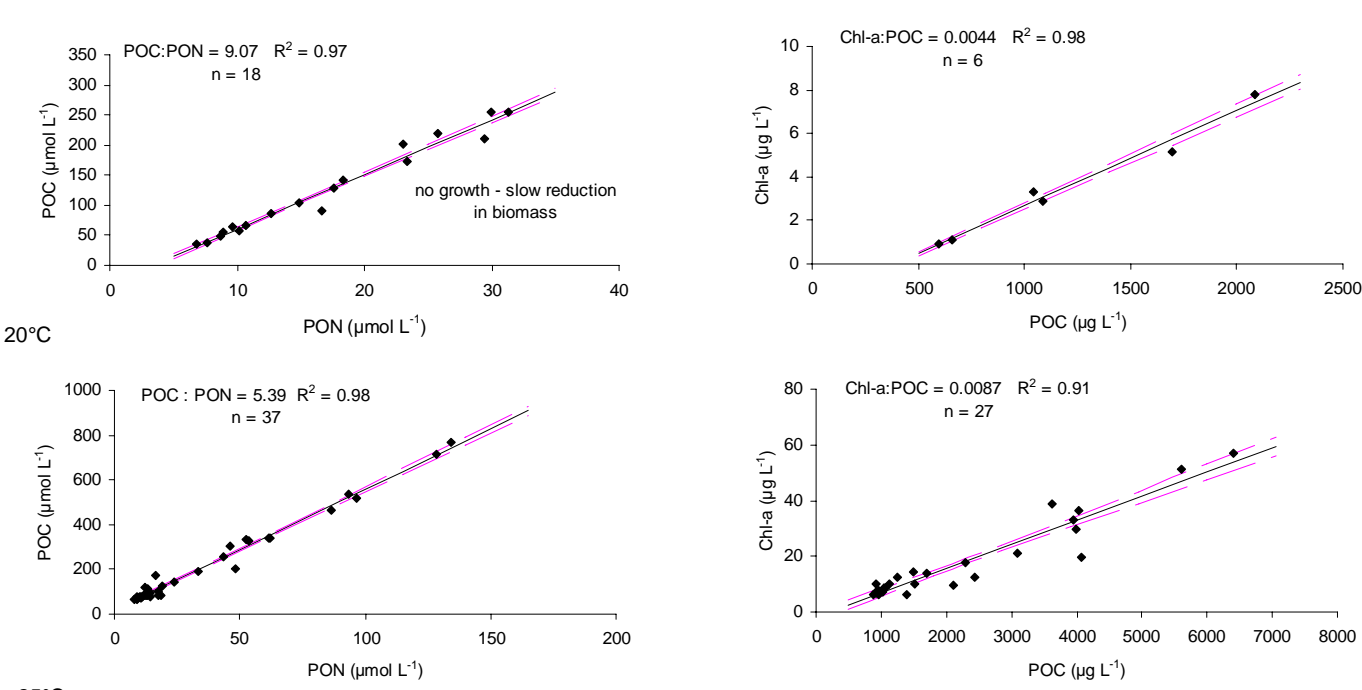

$25^{\circ}$
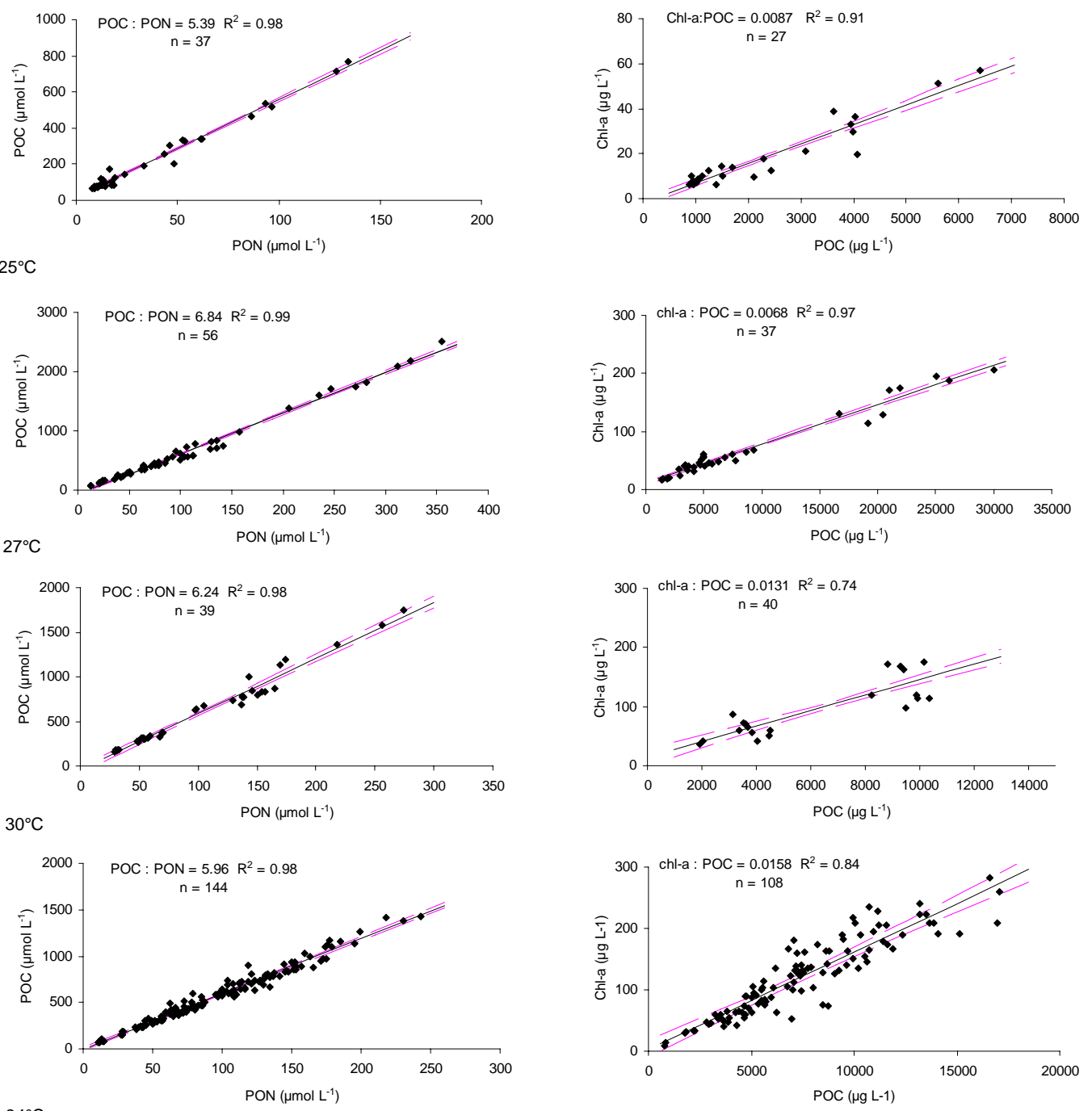

$34^{\circ} \mathrm{C}$
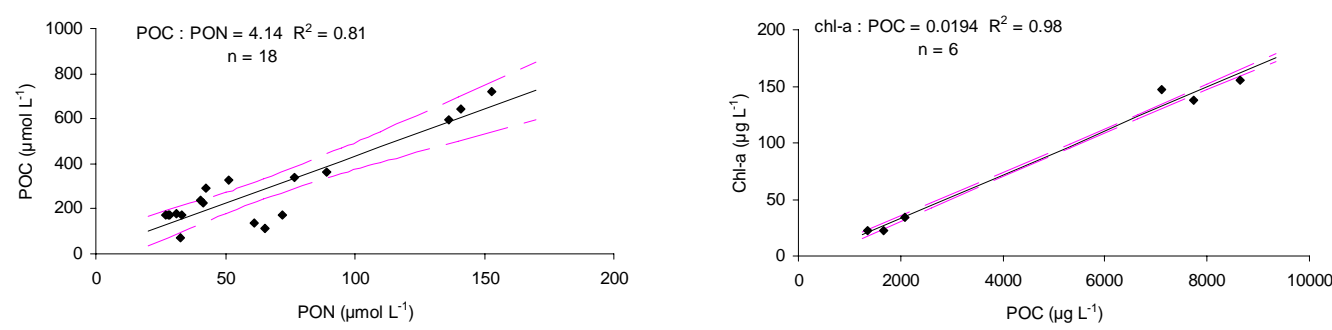

Fig. 2. Overview of POC:PON (mol:mol) and chlorophyll- $a$ :POC (weight:weight) stoichiometry of Trichodesmium IMS-101 at different temperatures. Solid black lines are derived from linear regressions of the data at various temperatures with their respective $95 \%$ convidence intervals plotted as dashed pink lines. The regression coefficient represents the stoichiometric ratio and is included in each plot together with the coefficient of determination $\left(\mathrm{R}^{2}\right)$ and the sample size $(\mathrm{n})$.

Biogeosciences, 4, 53-61, 2007

www.biogeosciences.net/4/53/2007/ 

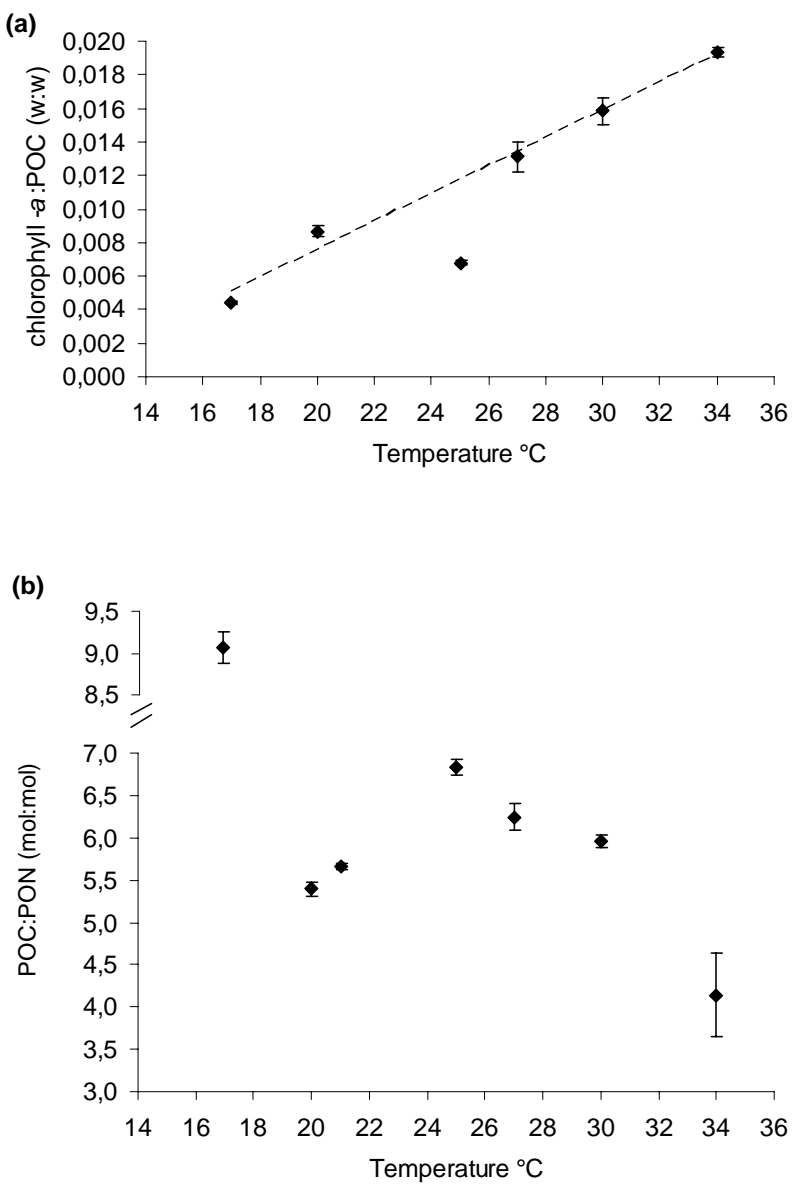

Fig. 3. Stoichiometry chlorophyll- $a$ :POC (weight:weight $(\mu \mathrm{g}$ $\mathrm{L}^{-1}: \mu \mathrm{g} \mathrm{L}^{-1}$ ), (a) and POC:PON (mol:mol, (b) of Trichodesmium IMS-101 as a function of growth temperature. Data points represent regression coefficients of the stoichiometric ratios at the respective temperatures and error bars denote the standard error of the regression coefficients. Please see Fig. 2 for the respective samples sizes (n) and coefficients of determination $\left(\mathrm{R}^{2}\right)$. The dashed line provides a linear fit to the data based on the regression:

$y=0.00084 x-0.0091, R^{2}=0.99$

where $y$ and $x$ are the chlorophyll- $a$ :POC ratio and temperature in ${ }^{\circ} \mathrm{C}$, respectively.

at $25^{\circ} \mathrm{C}$, which is close to the Redfield ratio (6.6). At higher temperatures the POC:PON ratio decreased again to a minimum value of 4.1 at $34^{\circ} \mathrm{C}$ (Fig. 2). A comparatively high POC:PON stoichiometry was measured at $17^{\circ} \mathrm{C}$ (9.1). However, it is not clear whether or not this was an artifact of lack of growth of Trichodesmium at this temperature.

Further, the cellular chlorophyll- $a$ to carbon ratio increased linearly from $0.0044(\mathrm{~g}: \mathrm{g})$ at $17^{\circ} \mathrm{C}$ to 0.0194 at $34^{\circ} \mathrm{C}$ (Fig. 3a) reflecting an acclimation response of the photosynthetic apparatus to temperature (Geider et al., 1997).

The data shown in Figs. 2 and 3 are derived from measurements throughout the growth period of the batch incu-
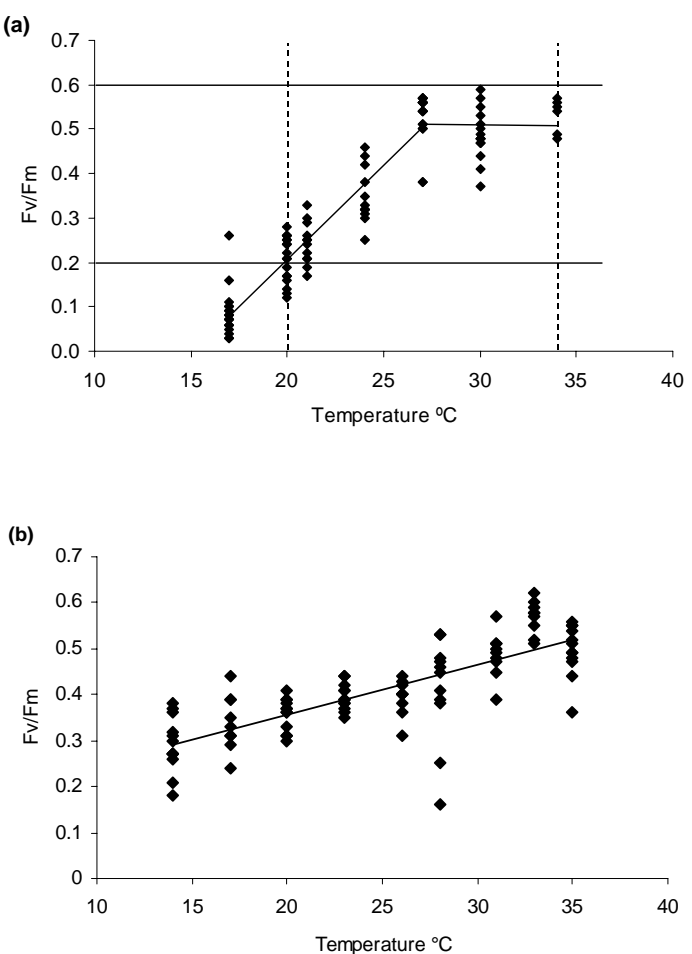

Fig. 4. (a): Photosynthetic quantum yield efficiency of only exponentially growing Trichodesmium IMS-101 batch cultures acclimated to various temperatures. The two solid horizontal lines indicate the theoretical minimum (0.2) and maximum (0.6) $\mathrm{F}_{v} / \mathrm{F}_{m}$ values for living cyanobacteria. The two vertical dashed lines indicate the temperature tolerance range of Trichodesmium IMS-101 $\left(20-34^{\circ} \mathrm{C}\right)$. (b): Photosynthetic quantum yield efficiency of Trichodesmium IMS-101 grown at $25^{\circ} \mathrm{C}$ and exposed to the respective temperatures of $\mathrm{F}_{v} / \mathrm{F}_{m}$ measurements for short duration (four $\mathrm{h}$ ).

bations. As previously reported by Mulholland and Capone (2001), POC:PON ratios varied over the growth period and were reduced during the exponential growth phase, which is characteristic of high $\mathrm{N}_{2}$-fixation. Nevertheless, in some of the experiments the exponential growth phase was very short, yielding very few of data points, which would make a regression analysis problematic. Furthermore, the contribution of the exponential growth phase data to the stoichiometric ratios derived from all data points of an experiment was insignificant in most cases. However, we did exclude data for cultures that were not acclimated to the incubation temperatures yet, which was the case for samples taken during the first two days of an experiment after transferring a culture to a different temperature.

\subsection{Photosynthetic response}

The photosynthetic quantum yield efficiency $\left(\mathrm{F}_{v} / \mathrm{F}_{m}\right)$ of cultures acclimated to their growth temperature increased from below 0.10 at $17^{\circ} \mathrm{C}$ up to a maximum quantumyield efficiency of 0.68 at $30^{\circ} \mathrm{C}$ (Fig. 4a). As there was 


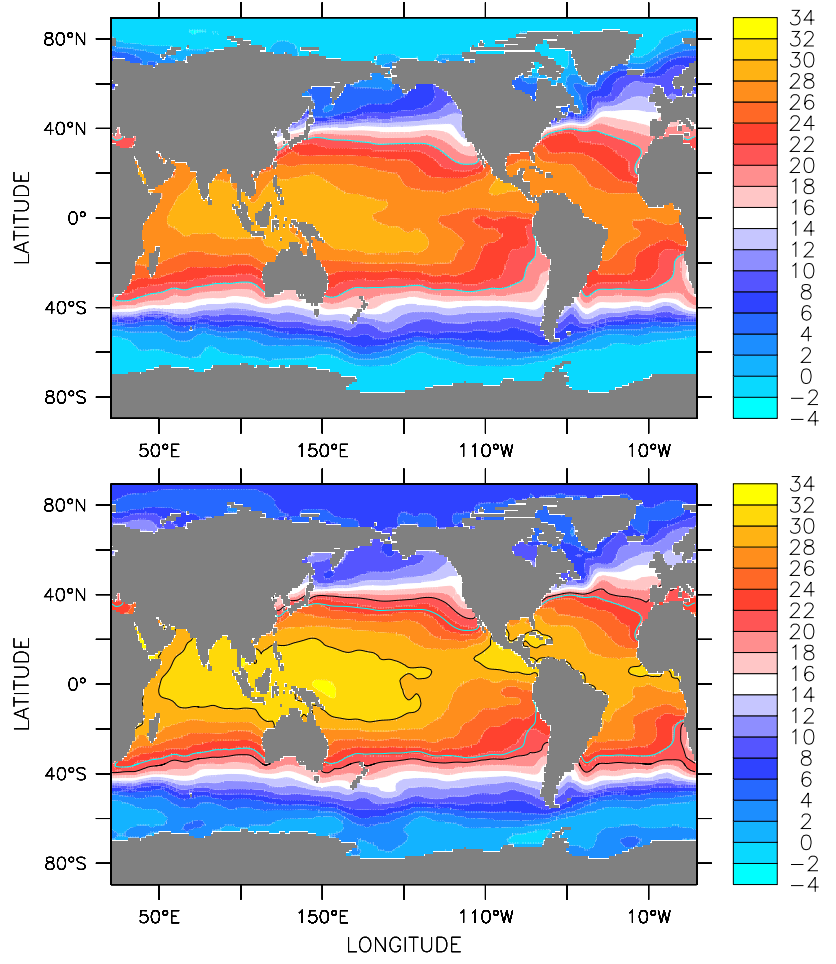

Fig. 5. The observed present-day annual mean sea surface temperature (top) in comparison to the annual mean sea surface temperature incremented by the modeled increase over the period 1990 to 2090 (bottom) based on HadCM3. In both plots, the cyan line indicates the maximum latitudinal boundary of the $20^{\circ} \mathrm{C}$ isotherm observed in 1990 . The black lines in the bottom plot indicate the 20 and $30^{\circ} \mathrm{C}$ isotherms predicted for 2090.

considerable variation of $\left(\mathrm{F}_{v} / \mathrm{F}_{m}\right)$ as a function of physiological differences during growth in batch cultures, only samples from the exponential growth phase were plotted in Fig. 4b. Here, the average quantum yield efficiency increased from 0.20 at the minimum feasible growth temperature $\left(20^{\circ} \mathrm{C}\right)$ to 0.52 at $27^{\circ} \mathrm{C}$ and thereafter remained constant up to $34^{\circ} \mathrm{C}$. Maximum values did not exceed 0.60 (Fig. 4b). In contrast, $\mathrm{F}_{v} / \mathrm{F}_{m}$ measurements of Trichodesmium grown at $25^{\circ} \mathrm{C}$ and transferred to a range of temperatures ( $4 \mathrm{~h}$ incubations) were positively correlated with temperature and increased linearly from approximately 0.25 at $14^{\circ} \mathrm{C}$ to the maximum of 0.60 at the maximum growth temperature $\left(34^{\circ} \mathrm{C}\right)$. This demonstrates that the photosynthetic apparatus adjusted slowly to changes in temperature. Measurements at $36^{\circ} \mathrm{C}$ showed reduced $\mathrm{F}_{v} / \mathrm{F}_{m}$ values again (Fig. $4 \mathrm{a}$ ).

3.4 Potential effects of predicted SST increase on Trichodesmium distribution

Climate models predict increases in sea surface temperature (SST) by up to $3^{\circ} \mathrm{C}$ by 2090 in our area of interest (20$30^{\circ} \mathrm{C}$ isotherms), accompanied by a poleward shift of the $20^{\circ} \mathrm{C}$ isotherm (Fig. 5). This will result in an $11 \%$ areal in- crease of Trichodesmium's potential geographic distribution. Moreover, maximum calculated SSTs will still be less than $34^{\circ} \mathrm{C}$, which will not limit the potential distribution of Trichodesmium in tropical waters. Nevertheless, a decrease in the area characterized by optimum growth and $\mathrm{N}_{2}$-fixation conditions $\left(24-30^{\circ} \mathrm{C}\right)$ by about $16 \%$ is anticipated (Fig. 5).

\section{Discussion}

Temperature per se does not restrict diazotrophic growth and diazotrophs can be encountered at temperatures close to freezing (Zielke et al., 2002; Pandey et al., 2004), yet the overall distribution of Trichodesmium in the contemporary ocean appears well constrained by seawater temperature $\left(\sim 20-30^{\circ} \mathrm{C}\right)$ (Capone et al., 1997). However, the correlation of Trichodesmium abundance with water temperature is generally attributed to oceanographic features associated with warm waters, such as shallow mixed layer depth, high light intensity, and oligotrophic conditions rather than a direct physiological response to temperature itself (Hood et al., 2004). Since surface water temperature and dissolved nitrate concentrations are significantly negatively correlated in the marine environment, it is not clear whether the global patterns of $\mathrm{N}_{2}$-fixation versus water temperature are due to an inhibition of nitrogenase by low temperatures or a selection against $\mathrm{N}_{2}$-fixers under conditions of high nitrate concentrations or both. In this work, we separated the effect of temperature from other factors (i.e. nutrients, light, and stratification) on diazotrophic growth and thus were able to demonstrate that, as suggested by Capone et al. (1997), seawater temperature sets a physiological constraint to the geographic distribution of Trichodesmium.

We are able to demonstrate that the strain IMS-101 of Trichodesmium is adapted to optimal growth at temperatures between 24 and $30^{\circ} \mathrm{C}$ and can tolerate water temperatures from 20 to $34^{\circ} \mathrm{C}$. Analogous to our results, positive correlations of Trichodesmium abundance and water temperature $\left(22-28 / 31^{\circ} \mathrm{C}\right)$ were also observed in field studies (Capone et al., 1997; Lin, 2002; Lugomela et al., 2002; Chen et al., 2003). However, our observation that cells can survive at $17^{\circ} \mathrm{C}$ for several weeks and experience a slow decrease in biomass can also explain the persistence of Trichodesmium transported to higher latitudes by oceanic currents (Carpenter, 1983; Lipschultz and Owens, 1996).

In contrast to our finding of an optimum temperature range between 24 and $30^{\circ} \mathrm{C}$, Staal et al. (2003) described a linear increase of nitrogen fixation up to a temperature of $36^{\circ} \mathrm{C}$ in short-term incubations ( $2 \mathrm{~min}, \mathrm{M}$. Staal, personal communication). Measurements published by Staal et al. (2003) most likely reflected nitrogenase enzyme kinetics, whereas data presented here describe temperature acclimated diazotrophic growth (Fig. 1). This is based on the physiological patterns of maximum nitrogen fixation activity, highest growth rates, cellular elemental composition, and photosynthetic quantum 
yield efficiency. The maximum growth rates and high nitrogen fixation rates between 24 and $30^{\circ} \mathrm{C}$ must be accompanied by high carbon fixation rates, which is expressed in near Redfield POC:PON stoichiometry. As an effect of temperature though, a larger fraction of fixed $\mathrm{N}_{2}$ may be released and not incorporated into the cells when either carbon fixation is insufficient, or cells may become leakier due to increased membrane permeability at higher temperatures. The temperature acclimation of the chlorophyll- $a$ :POC ratio reflects the need to reduce light absorption at low temperatures in order to equilibrate with lower enzyme activity, while this mechanism is relieved at higher temperatures. Factors such as light and nutrient regimes directly interact with temperature and will also play determinant roles. Photosynthetic organisms will acclimate to both light and temperature by adjusting the balance between light energy absorption and the rate of the dark reaction of photosynthesis, i.e. by increasing light absorption in low light and decreasing it at low temperature (Geider et al., 1997; Miskiewicz et al., 2002). The photosynthetic quantum yield efficiency clearly reflects a physiological adaptation to the temperature tolerance range of Trichodesmium (IMS-101). In short term incubations $\mathrm{F}_{v} / \mathrm{F}_{m}$ increased linearly up to the physiological maximum temperature of $34^{\circ} \mathrm{C}$. Measurements of cultures growing exponentially at the respective temperatures though reveal that the photosystem II operated at minimum efficiency at $20^{\circ} \mathrm{C}$ and saturated at maximum efficiencies between 27 and $34^{\circ} \mathrm{C}$. Thus, the temperature tolerance range of Trichodesmium IMS-101 grown at $100 \mu \mathrm{mol}$ quanta $\mathrm{m}^{-2} \mathrm{~s}^{-1}$ is also confined by the general range of photosynthetic quantum yield efficiency for cyanobacteria (0.20-0.60, Fig. 4a). One can hypothesize that the high temperature optimum for Trichodesmium growth leads to a better tolerance of high light intensity, which is characteristic of tropical and subtropical regions.

While we cannot fully explain the biochemical basis for the physiological constraint to the observed temperature range, a combination of several mechanisms is likely. In Trichodesmium, the timing of nitrogen fixation and photosynthesis has been shown to be under the control of a circadian rhythm (Chen et al., 1998) and the temperature tolerance range may be in part set by the temperature compensation range of the circadian clock. Further, the dark reaction of photosynthesis is temperature dependent due to enzyme kinetics and membrane permeability (Falkowski and Raven, 1997). In addition, it has been shown for terrestrial plants that Rubisco activase has a lower temperature tolerance than Rubisco itself. Rubisco activase is not capable of maintaining Rubisco, the global enzyme that is essentially responsible for photosynthetic carbon acquisition, in an active form at growth temperatures outside the thermal environment to which the organism is adapted (Crafts-Brandner and Salvucci, 2000; Salvucci and Crafts-Brandner, 2004a, b). It is possible, but remains to be demonstrated, that such a mechanism also limits the photophysiology of Trichodesmium at the high end of the temperature tolerance range.

Overall, the mechanisms determining the optimal growth temperature in microorganisms are poorly understood but, at the most basic level, adaptions to extreme cold or heat have a genetic basis. Genomic analysis of psychrophilic bacteria for example revealed that cold-adaptation is not just a function of a specific set of proteins but also dependent on the general amino acid composition of the proteins and membrane fluidity and permeability (Methe et al., 2005). Diazotrophs in general can grow at all temperatures. In particular, $O s$ cillatoria, a close relative of Trichodesmium is found in the Antarctic (Pandey et al., 2004). Phylogenetic analysis of the hetR gene, which is most likely involved in heterocyst and diazocyst development, revealed a high diversity level within the Trichodesmium clade (Mes and Stal, 2005). Thus, although the strain Trichodesmium IMS-101 did not adapt to growth at higher and lower temperatures in our experiments, other uncultivated strains may be capable of growing outside this temperature range.

A community shift towards other diazotrophs may also be possible. Until recently, the significance of unicellular $\mathrm{N}_{2}$-fixers has been underestimated (Montoya et al., 2004), but latest observations suggest that these diazotrophs also thrive at the $26-30^{\circ} \mathrm{C}$ temperature range (Mazard et al., 2004; Falcón et al., 2005; Langlois et al., 2005). However, a few samples from temperatures below $20^{\circ} \mathrm{C}$ also contained nifH genes, indicative of the presence of diazotrophs, suggesting that some marine nitrogen fixers may also dwell in cold water (Langlois et al., 2005). Whether or not these unicellular cyanobacteria are actively fixing nitrogen, or if they can potentially fill niches for nitrogen fixers at the lower or higher temperature ranges remains to be investigated.

Acknowledging that we lack information on the physiological variability within the genus Trichodesmium, we suggest that future changes in SST may result in an 11\% areal increase in Trichodesmium's potential geographic distribution due to the poleward shift of the $20^{\circ} \mathrm{C}$ isotherm, while the maximum calculated SSTs $\left(34^{\circ} \mathrm{C}\right)$ will not be limiting diazotrophy of Trichodesmium in tropical waters. However, because of the much higher $\mathrm{N}_{2}$-fixation rates and the growth physiology of Trichodesmium in the $24-30^{\circ} \mathrm{C}$ SST range, the effect of the $16 \%$ decrease in the area characterized by optimum growth and $\mathrm{N}_{2}$-fixation conditions $\left(24-30^{\circ} \mathrm{C}\right)$ is likely to outweigh the positive effect of the latitudinal increase of the total area (Fig. 5). Thus, the predicted overall increase in sea surface temperature may result in a net decrease of $\mathrm{N}_{2}$-fixation by Trichodesmium by the end of this century. The effects on oceanic nitrogen cycling may be significant, taking the global importance of this diazotroph into account (Capone et al., 1997; Capone and Carpenter, 1999). As mentioned earlier, these predictions are based solely on the observed dependence of Trichodesmium IMS-101 growth on temperature. Additionally, our hypothesis is based on SST only and does not consider possible changes in nutrient supply and light conditions, which will also be affected 
by SST increase and are, to date, more difficult to predict than changes in SST.

Current predictions of future marine nitrogen fixation diverge. In contrast to our findings, Boyd and Doney (2002) predict a future increase of $\mathrm{N}_{2}$-fixation by $27 \%$ (from 80 to $94 \mathrm{Tg} \mathrm{yr}^{-1}$ ) due to a floristic shift towards diazotrophy by Trichodesmium caused by combined effects of mixed layer depth (MLD), stratification, and nutrient distribution. Time series measurements near Hawaii (Karl et al., 1997) support this trend. Although SSTs in this area of the North Pacific are predicted to increase by almost $3^{\circ} \mathrm{C}$ (Figs. 5a and b) they will not exceed the physiologically optimal range. Nevertheless, large regions of the tropical and subtropical oceans are predicted to fall outside the optimal range. Particularly, temperatures rising above $30^{\circ} \mathrm{C}$ in $\mathrm{N}_{2}$-fixation hotspots may result in significant changes of the regional nitrogen budgets. In the North Atlantic, for example, SSTs are predicted to exceed $30^{\circ} \mathrm{C}$ in the Caribbean Sea as well as in equatorial waters off West Africa, which are currently hotspots of $\mathrm{N}_{2}$ fixation in a model based on field observations, MLD and light (Hood et al., 2004). Similarly high SSTs are predicted for the western Pacific and a large part of the Indian Ocean, which both are characteristic provinces for present-day Trichodesmium abundance (LaRoche and Breitbarth, 2005).

Whether a global SST increase in the future ocean will result in a decrease in Trichodesmium or lead to a community shift towards other diazotrophs rests on the physiological temperature dependence of nitrogen fixation and on the relative importance of temperature compared to other factors such as water column stability, nutrient availability and light intensity. Conversely, physical and chemical factors other than temperature may also determine the development of nitrogen fixation hotspots in the future ocean.

In conclusion, our results demonstrate that the temperature adaptation of Trichodesmium IMS-101 controls the geographic distribution of this species. Based on the physiological constraints of diazotrophic growth of Trichodesmium IMS-101, we suggest reduced fixed nitrogen input by Trichodesmium in response to the SST increase predicted for the end of this century. Although SSTs are expected to rise essentially everywhere, the area of surface waters with temperatures in the physiologically optimal range for growth of Trichodesmium will likely decline. We expect that, within the areal limits imposed by the SST, a combination of other controlling factors such as MLD, light, and nutrient regimes (including iron) will further influence the distribution of Trichodesmium. Considering the large fraction of $\mathrm{N}_{2}$ fixation by Trichodesmium on total oceanic nitrogen input, the predicted ecophysiological changes to this diazotroph may cause significant changes in global biogeochemical cycles. Nevertheless, because little is known about temperature selection of other diazotrophs, we do not know what the overall dynamics of $\mathrm{N}_{2}$ fixation in the future ocean will be. As $\mathrm{N}_{2}$-fixation in currently available ocean biogeochemical circulation models is based on Trichodesmium, it may be necessary to adjust their parameterizations in view of the temperature-diazotrophic growth relationship presented here, and to consider taking into account other diazotrophs as well.

Acknowledgements. We thank G. Petrick and U. Rabsch for technical advice and assistance. We also thank J. Waterbury for the axenic Trichodesmium IMS-101 culture. Further, we are indebted to M. Voss and an anonymous reviewer for their helpful comments on the manuscript. The experimental work was funded by EU-project IRONAGES (EVK2-CT-1999-00031) awarded to J. LaRoche.

Edited by: S. W. A. Naqvi

\section{References}

Boyd, P. W. and Doney, S. C.: Modeling regional responses by marine pelagic ecosystems to global climate change, Geophys. Res. Lett., 29(16), 53,1-53,4, 2002.

Breitbarth, E., Mills, M. M., Friedrichs, G., and LaRoche, J.: The bunsen gas solubility coefficient of ethylene as a function of temperature and salinity and its importance for nitrogen fixation assays, Limnology and Oceanography: Methods, 2, 282-288, 2004.

Capone, D. G.: Determination of nitrogenase activity in aquatic samples using the acetylene reduction procedure, Handbook of Methods in Aquatic Microbial Ecology, 1993.

Capone, D. G. and Carpenter, E. J.: Nitrogen fixation by marine cyanobacteria: historical and global perspectives, Bulletin de l'Oceanographique Monaco, special issue 19, 235-256, 1999.

Capone, D. G., Subramaniam, A., Montoya, J. P., et al.: An extensive bloom of the N-2-fixing cyanobacterium Trichodesmium erythraeum in the central Arabian Sea, Marine Ecol. Prog. Ser. 172, 281-292, 1998.

Capone, D. G., Zehr, J. P., Pearl, H. W., et al.: Trichodesmium, a globally significant marine cyanobacterium, Science, 276, 5316, 1221-1229, 1997.

Carpenter, E. J.: Physiology and ecology of marine planktonic Oscillatoria (Trichodesmium), Mar. Biol. Lett., 4, 69-85, 1983.

Carpenter, E. J., Subramaniam, A., and Capone, D. G.: Biomass and primary productivity of the cyanobacterium Trichodesmium spp. in the tropical N Atlantic ocean, Deep-Sea Res. I, 51(2), 173-203, 2004.

Chen, Y. B., Dominic, B., Mellon, M. T., and Zehr, J. P.: Circadian rhythm of nitrogenase gene expression in the diazotrophic filamentous nonheterocystous cyanobacterium Trichodesmium sp. strain IMS 101, J. Bacteriol., 180(14), 3598-3605, 1998.

Chen, Y. B., Zehr, J. P., and Mellon, M.: Growth and nitrogen fixation of the diazotrophic filamentous nonheterocystous cyanobacterium Trichodesmium sp. IMS 101 in defined media: Evidence for a circadian rhythm, J. Phycology, 32(6), 916-923, 1996.

Chen, Y. L. L., Chen, H. Y., Lin, Y. H., et al.: Distribution and downward flux of Trichodesmium in the South China Sea as influenced by the transport from the Kuroshio Current, Marine Ecol.-Prog. Ser., 259, 47-57, 2003.

Crafts-Brandner, S. J. and Salvucci, M. E.: Rubisco activase constrains the photosynthetic potential of leaves at high temperature 
and $\mathrm{CO}_{2}$, Proceedings of the National Academy of Sciences of the United States of America, 97(24), 13 430-13 435, 2000.

Delworth, T. L., Stouffer, R. J., Dixon, K. W., et al.: Review of simulations of climate variability and change with the GFDL R30 coupled climate model., Clim. Dyn., 19, 555-574, 2002.

Ehrhard, M. and Koeve, W.: Determination of particulate organic carbon and nitrogen, Methods of Seawater Analysis, WileyVCH, 437-444, 1999.

Falcón, L. I., Pluvinage, S., and Carpenter, E. J.: Growth kinetics of marine unicellular N2-fixing cyanobacterial isolates in continuous culture in relation to phosphorus and temperature, Marine Ecol. Prog. Ser., 285(3-9), 2005.

Falkowski, P. G. and Raven, J. A.: Aquatic Photosynthesis, Blackwell Science, Malden, MA, USA, 375, 1997.

Fennel, K., Spitz, Y. H., Letelier, R. M., et al.: A deterministic model for N-2 fixation at stn. ALOHA in the subtropical North Pacific Ocean, Deep-Sea Res. II, 49(1-3), 149-174, 2001.

Geider, R. J. and La Roche, J.: Redfield revisited: variability of $\mathrm{C}: \mathrm{N}: \mathrm{P}$ in marine microalgae and its biochemical basis, European J. Phycol., 37(1), 1-17, 2002.

Geider, R. J., MacIntyre, H. L., and Kana, T. M.: Dynamic model of phytoplankton growth and acclimation: Responses of the balanced growth rate and the chlorophyll a:carbon ratio to light, nutrient-limitation and temperature, Marine Ecol. Prog. Ser., 148(1-3), 187-200, 1997.

Gordon, C., Cooper, C., Senio, C. A., et al.: The simulation of SST, sea ice extents and ocean heat transports in a version of the Hadley Centre coupled model without flux adjustments., Clim. Dyn., 16, 147-168, 2000.

Gruber, N. and Sarmiento, J. L.: Global patterns of marine nitrogen fixation and denitrification, Global Biogeochem. Cycles, 11(2), 235-266, 1997.

Hood, R. R., Bates, N. R., Capone, D. G., and Olson, D. B.: Modeling the effect of nitrogen fixation on carbon and nitrogen fluxes at BATS, Deep-Sea Res. II, 48(8-9), 1609-1648, 2001.

Hood, R. R., Coles, V. J., and Capone, D. G.: Modeling the distribution of Trichodesmium and nitrogen fixation in the Atlantic Ocean, J. Geophys. Res., 109(6), L06301, doi:10.1029/2002JC001753, 2004.

Karl, D., Letelier, R., Tupas, L., et al.: The role of nitrogen fixation in biogeochemical cycling in the subtropical North Pacific Ocean, Nature, 388, 6642, 533-538, 1997.

Kolbowski, J. and Schreiber, U.: Computer-controlled phytoplankton analyzer based on 4-wavelengths PAM chlorophyll fluorometer, Photosynthesis: from Light to Biosphere, V, 825-828, 1995.

Langlois, R. J., LaRoche, J., and Raab, P. A.: Diazotrophic diversity and distribution in the tropical and subtropical Atlantic ocean, Appl. Environ. Microbiol., 71(12), 7910-7919, 2005.

LaRoche, J. and Breitbarth, E.: Importance of the diazotrophs as a source of new nitrogen in the ocean, J. Sea Res., 53(1-2), 67-91, 2005.

Letelier, R. M. and Karl, D. M.: Role of Trichodesmium spp. in the productivity of the subtropical North Pacific Ocean, Marine Ecol. Prog. Ser., 133(1-3), 263-273, 1996.

Levitus, S. and Boyer, T.: Temperature, World Ocean Atlas 1994, 4, 1994.

Lin, Y. H.: The spatial and temporal distributions of nitrogen fixation cyanobacterium Trichodesmium spp. and Richelia intracellularis in South China Sea, Master's Thesis, National Sun Yat-
Sen University, Taiwan, 2002.

Lipschultz, F. and Owens, N. J. P.: An assessment of nitrogen fixation as a source of nitrogen to the North Atlantic Ocean, Biogeochemistry, 35(1), 261-274, 1996.

Lugomela, C., Lyimo, T. J., Bryceson, I., et al.: Trichodesmium in coastal waters of Tanzania: diversity, seasonality, nitrogen and carbon fixation, Hydrobiologia, 477, 1-13, 2002.

Mazard, S. L., Fuller, N. J., Orcutt, K. M., et al.: PCR Analysis of the Distribution of Unicellular Cyanobacterial Diazotrophs in the Arabian Sea, Appl. Environ. Microbiol., 70(12), 7355-7364, 2004.

Mes, T. H. M. and Stal, L. J.: Variable selection pressures across lineages in Trichodesmium and related cyanobacteria based on the heterocyst differentiation protein gene hetR, Gene, 346, 163$171,2005$.

Methe, B. A., Nelson, K. E., Deming, J. W., et al.: The psychrophilic lifestyle as revealed by the genome sequence of $\mathrm{Col}$ wellia psychrerythraea $34 \mathrm{H}$ through genomic and proteomic analyses, Proceedings of the National Academy of Sciences of the United States of America, 102(31), 10 913-10 918, 2005.

Miskiewicz, E., Ivanov, A. G., and Huner, N. P. A.: Stoichiometry of the photosynthetic apparatus and phycobilisome structure of the cyanobacterium Plectonema boryanum UTEX 485 are regulated by both light and temperature, Plant Physiology, 130(3), 1414-1425, 2002.

Montoya, J. P., Holl, C. M., Zehr, J. P., et al.: High rates of N2 fixation by unicellular diazotrophs in the oligotrophic Pacific Ocean, Nature, 430, 1027-1031, 2004.

Montoya, J. P., Voss, M., Kaehler, P., and Capone, D. G.: A simple, high-precision, high-sensitivity tracer assay for N-2 fixation, Appl. Environ. Microbiol., 62(3), 986-993, 1996.

Mulholland, M. R. and Capone, D. G.: Stoichiometry of nitrogen and carbon utilization in cultured populations of Trichodesmium IMS-101: Implications for growth, Limnology and Oceanography, 46, 2, 436-443, 2001.

Pandey, K. D., Shukla, S. P., Shukla, P. N., et al.: Cyanobacteria in Antarctica: Ecology, physiology and cold adaptation, Cellular and Molecular Biology, 50(5), 575-584, 2004.

Salvucci, M. E. and Crafts-Brandner, S. J.: Inhibition of photosynthesis by heat stress: the activation state of Rubisco as a limiting factor in photosynthesis, Physiol. Plant, 120(2), 179-186, 2004a.

Salvucci, M. E. and Crafts-Brandner, S. J.: Relationship between the heat tolerance of photosynthesis and the thermal stability of rubisco activase in plants from contrasting thermal environments, Plant Physiology, 134(4), 1460-1470, 2004b.

Sharp, J. H.: Improved analysis for particulate organic carbon and nitrogen from seawater, Limnology and Oceanography, 19, 345350, 1975.

Staal, M., Meysman, F. J. R., and Stal, L. J.: Temperature excludes $\mathrm{N}$-2-fixing heterocystous cyanobacteria in the tropical oceans, Nature, 425, 6957, 504-507, 2003.

Welschmeyer, N. A.: Fluorometric analysis of chlorophyll- $a$ in the presence of chlorophyll- $b$ and phaeopigments, Limnology and Oceanography, 39(8), 1985-1992, 1994.

Zielke, M., Ekker, A. S., and Olsen, R. A.: The Influence of Abiotic Factors on Biological Nitrogen Fixation in Different Types of Vegetation in the High Arctic, Svalbard, Arctic, Antarctic, and Alpine Res., 34(3), 293-299, 2002. 